\title{
Depression and Multimorbidity in Psychiatry and Primary Care
}

\author{
Tom O'Dowd, MD
}

$\mathbf{I}$ $\mathrm{t}$ is well known that depression and multiple morbidities are common bedfellows. Yet the conclusion by Smith et $\mathrm{al}^{1}$ in this issue that over $68 \%$ of patients with depression had "at least 1 comorbid physical health condition" is striking. Their conclusion that "physical health comorbidity appears to be the norm rather than the exception in depressive disorder" is powerful enough to set an agenda and perhaps challenge how we practice medicine. We often criticize ourselves about practicing medicine in clinical silos that are based on systems while patients suffer illnesses that do not fit very well into these silos. ${ }^{2}$ Currently, psychiatrists treat depression and other mental illnesses while family physicians and internists battle with the physical illnesses in the same patient.

In daily consultations, family doctors see much subthreshold depressive symptoms, ${ }^{3}$ which psychiatrists often call dysphoria but which can also be labeled as unhappiness. Crucially of course, the symptoms of unhappiness, pain, and impaired function overlap with depression. Such symptoms, when they are part of multimorbidity, may be a form of grief over the progressive loss of function that chronic illness brings about. ${ }^{4}$ However, clinical assessment incorporating unhappiness by a family doctor may underestimate the patient's mental health, especially when the patient is well known to the doctor. ${ }^{5}$ Depression is one of those conditions that can easily be overlooked in such a clinical circumstance. It is reasonable to expect patients with multiple chronic illnesses to have low mood, loss of pleasure, functional impairment, pain, and grief as part of their overall illness package. Part of the art of family medicine is to work out when unhappiness has given way to depression and when to begin treatment.

Modern psychiatry classification places little or no weight on the presence or absence of precipitating factors in major depression and does not now distinguish between reactive or endogenous depression. In primary care medicine, precipitating factors and reaction to events and illnesses are frequently part of a pragmatic diagnosis of depression with the consequent prescribing of antidepressants. Are there 2 clinical depressions? One in psychiatry and another in primary care? One where reactive depression is a frequent and pragmatic diagnosis and one where it is not given much or any weight.

Psychiatrists often see patients with depression who also have multiple other physical illnesses that may or may not play a part in the origin of their depression. Psychiatrists

Submitted:September 11, 2014; accepted September 15, 2014. Corresponding author: Tom O'Dowd, MD, Trinity College Dublin, Ireland (todowd@tcd.ie).

J Clin Psychiatry 2014;75(11):e1319-e1320 (doi:10.4088/JCP.14com09504). (c) Copyright 2014 Physicians Postgraduate Press, Inc. usually leave the physical illnesses to others to manage and may take insufficient interest in the resultant polypharmacy and adherence issues that arise in multimorbidity. As a consequence, functional improvement with better motivation may be attributed to better control of the physical illness, including better adherence, than the result of good psychiatric care. According equal priority to mental and physical conditions has been advocated for adequate management of both and/or the reduction of disability. ${ }^{6}$

It is well known in epidemiologic circles that the betteroff live longer than the less well-off. Urban design has responded to the wishes of the well-off to live separately from the less well-off. This form of habitation allows researchers to examine health on a geographical area basis. ${ }^{7}$ Family doctors who work in deprived areas usually do not have the resources to match their clinical need while the overwhelming workload and rates of ill health have often gone unnoticed and poorly described. The paper by Smith et $\mathrm{al}^{1}$ compares the rates of illness among the most deprived and the least deprived in urban Scotland. It shows that chronic obstructive pulmonary disease is over twice as common in deprived areas than in better-off areas, and interestingly the nonspecific symptom of pain occurs in one-third of the mostdeprived quintile and nearly one-fifth of the least-deprived quintile. Socioeconomics as a determinant of health is often poorly studied in many of our health care systems because it is seen as a criticism of the government of the day. The seminal Black report ${ }^{8}$ on inequalities in health in the United Kingdom was published over a public holiday in August, as 260 photocopied documents, in order to escape public attention. It is likely that if it had been published properly it would never have become news and therefore come to such broad international attention. ${ }^{8}$

Patients in deprived areas often have lower educational attainment and find it more difficult to process the information to help them adopt healthier lifestyles. Hence, the enormous variation in chronic obstructive pulmonary disease rates in the Scottish sample, ${ }^{1}$ which is most likely related to higher rates of smoking tobacco among the poor. Summoning the personal resources required for daily living in deprived areas takes its toll and is expressed as a more painful existence than for those living in better circumstances.

With mounting evidence of the link between health and socioeconomic status should come an awareness that resources in terms of clinical workforce are important. ${ }^{9}$ Workforce planning in the area of high deprivation with its high prevalence of chronic, mental, and physical illnesses is a legitimate outcome for an alliance between psychiatrists and family doctors. Doctors, particularly in market force health economies, are more likely to work among the better off where clinical need is less than in deprived areas. It is 
clear that patients with multiple morbidities in areas of deprivation need generalist physical and mental health physicians to provide good clinical care. Both psychiatry and family medicine have a particular relevance to the sick and the poor who wish to be cared for in their own communities.

There is much research in the multimorbidity area viewing it from the single system or disease end of the diagnostic prism. There is also the risk that multimorbidity research is merely old wine in new bottles or that it runs the risk of being sequestered in primary care or geriatrics. It is much more substantial than that. ${ }^{10}$

When family medicine was finding its feet in the 1970s and 1980s, it drew strongly from psychiatry and in particular from psychiatrists like Michael Balint. ${ }^{11}$ Too often psychiatry and family medicine seem to have gone their separate ways, estranged even, for a variety of reasons. Depression is a good example of definitional variation where pragmatism seems to hold more sway in primary care than in psychiatry. Yet both disciplines have the moral and vocational basis for a clinical alliance that can be built around advocacy, research, and integration of services in the area of multimorbidity. The overlap between psychiatry and family medicine is the basis for a training curriculum, which will allow the emergence of more integrated models of care between primary and secondary care as discussed in the Smith et al ${ }^{1}$ paper in this issue.
Author affiliations: Trinity College Dublin, Ireland.

Potential conflicts of interest: None reported.

Funding/support: None reported.

\section{REFERENCES}

1. Smith DJ, Court H, McLean G, et al. Depression and multimorbidity: a crosssectional study of 1,751,841 patients in primary care. J Clin Psychiatry. 2014;75(11):1202-1208.

2. Bower P, Macdonald W, Harkness E, et al. Multimorbidity, service organization and clinical decision making in primary care: a qualitative study. Fam Pract. 2011;28(5):579-587.

3. Depression in adults: the treatment and management of depression in adults. NICE guideline 90. Guidance.nice.org.uk/cg90. Updated October 2009. Accessed September 23, 2014.

4. Kralik D, Telford K. Transition in Chronic Illness-Grief and Loss. RDNS Research Unit. 2005. http://www.chronicpainaustralia.org.au/files/ Booklet\%202\%20-\%20Grief\%20and\%20Loss.pdf. Updated November 2005. Accessed September 29, 2014.

5. Coventry PA, Hays R, Dickens C, et al. Talking about depression: a qualitative study of barriers to managing depression in people with long term conditions in primary care. BMC Fam Pract. 2011;12(1):10.

6. Scott KM, Von Korff M, Alonso J, et al. Mental-physical co-morbidity and its relationship with disability: results from the World Mental Health Surveys. Psychol Med. 2009;39(1):33-43.

7. Wilkinson RG, Pickett K. The Spirit Level: Why More Equal Societies Almost Always Do Better. New York, NY: Bloomsbury Press. 2009.

8. Inequalities in Health: Report of a Research Working Group. London, UK: DHSS; 1980.

9. Coping with needs, demands and resources. The second meeting of "General Practitioners at the Deep End." Glasgow, Scotland: January 22, 2010. http:// www.gla.ac.uk/media/media_146571_en.pdf. Accessed September 23, 2014.

10. Mercer SW, Smith SM, Wyke S, et al. Multimorbidity in primary care: developing the research agenda. Fam Pract. 2009;26(2):79-80.

11. Balint M. The Doctor, His Patient and the Illness. Edinburgh, Scotland: Churchill Livingston; 1986 